\title{
A IMPORTÂNCIA SOCIAL E SIMBÓLICA DO MITO: DA ANTIGUIDADE CLÁSSICA AO ESTABELECIMENTO DA MITOLOGIA COMO CIÊNCIA
}

\section{MYTH AND IMAGINARY: THE MYTH SOCIO-IMAGETICAL IMPORTANCE THROUGH THE OCCIDENTAL WORLD}

\author{
Ana Maria Saldanha ${ }^{1}$
}

\begin{abstract}
Resumo: O mito corresponde à narração de um tempo passado original, precursor de todos os tempos, nos quais poderemos encontrar os modelos e exemplos que determinam e dão sentido à vida. Tendo acompanhado o Homem desde os primórdios da humanidade, o mito encontra-se enraizado nos comportamentos humanos, explicando simbolicamente factos humanos e naturais. Com este trabalho, procuramos compreender a importância social e simbólica do mito, ao longo das diferentes sociedades humanas, de forma a compreender ontologicamente quer a função social do mito, quer o estabelecimento da mitologia como ciência.
\end{abstract}

Palavras-chave: mito, mitologia, imaginário social, representações simbólicas, sociedades humanas

Summary: A myth is a narration of an original past time, precursor of all times, in which we can find the models and examples that determine and give meaning to life. Having accompanied man since the beginnings of mankind, myth is rooted in human behavior, symbolically explaining human and natural facts. With this work, we try to understand the social and symbolic importance of the myth, throughout the occidental human society, in order to understand ontologically the social function of the myth and subsequently the establishment of a new science: the mitology.

Keywords: myth, mythology, social imaginary, symbolic representations, human societies

\footnotetext{
${ }^{1}$ Ana Maria Saldanha tem um pós-Doutoramento em Sociologia da Literatura pela Faculdade de Ciências e Letras da Universidade Estadual de São Paulo (FCLAr-UNESP). É Doutorada em Lettres, Langues et Sciences Humaines, Spécialité: Etudes luso-brésiliennes pela Université Stendhal-Grenoble III (França) e em Estudos Literários - Especialidade em Literatura Comparada pela Faculdade de Letras da Universidade de Lisboa (FL-UL). Tem Mestrado em Langues, Lettres et Civilisations Etrangères pela Université StendhalGrenoble III (França) e Licenciatura em Línguas e Literaturas Modernas, variante de Estudos Portugueses, pela Faculdade de Ciências Sociais e Humanas da Universidade Nova de Lisboa (FCSH-UNL). Atualmente, é Professora Adjunta Convidada na Escola Superior de Línguas e Tradução (ESLT) do Instituto Politécnico de Macau (IPM), na Região Administrativa Especial de Macau (RAEM) (China).
} 


\section{Introdução}

São várias as tentativas de explicação do mito, sendo a mais frequente a que considera a criação mítica como uma forma de compreensão dos fenómenos humanos e naturais. Do ponto de vista semântico, a palavra grega mythos diz respeito, por um lado, à palavra, ao discurso, e, por outro, à estória, a uma narrativa desprovida de sentido histórico. Na época clássica grega, o termo grego mythos inseria-se numa narrativa poética, podendo significar mito, legenda, fábula ou, simplesmente, estória ${ }^{2}$.

O mito corresponde à narração de um tempo passado original, precursor de todos os tempos, nos quais poderemos encontrar os modelos e exemplos que determinam e dão sentido à vida. Tendo acompanhado o Homem desde os primórdios da humanidade, o mito encontra-se enraizado nos comportamentos humanos, explicando simbolicamente factos humanos e naturais. Sendo a forma transdiscursiva mais primitiva de o Homem se relacionar com o Universo, o mito interliga-se com este através de processos imagéticos, acompanhando o progresso e crescimento da sociedade.

Confundindo-se com a própria realidade, o mito era, nos seus primórdios, a própria vida, um modo de viver e de atuar, no qual a realidade, passando para um segundo plano, contribuía para a reanimação do próprio mito: «O mito fracassa em dar ao homem mais poder material sobre o meio. Apesar de tudo, dá ao homem a ilusão [...] de que ele pode entender o universo e de que ele entende, de facto, o universo» (LEVI-STRAUSS, 2000, p. 32). Nesta fase mítica da humanidade, o homem situa-se no que Freud considera ser «un système intellectuel, la première théorie complète du monde»(FREUD, 1986, p. 110), a fase animista: «D'après cette conception, le monde serait peuplé d'un grand nombre d'êtres spirituels, bienveillants ou malveillants à l'égard des hommes qui attribuent à ces esprits et démons la cause de tout ce qui se produit dans la nature» (FREUD, 1986, p. 90). Nesta fase, a «intuição primitiva é a de que o mundo constitui um todo, um conjunto vivo, de que as inúmeras realidades singulares - coisas, situações, eventos e, obviamente, também os homens - são precisamente participantes»(ADRIANI, 1997, p. 18).

\footnotetext{
${ }^{2}$ Este facto obriga o tradutor de grego clássico a escolher um dos termos em função dos casos relatados pelos autores. Assim, quando se trata de traduzir mythos no quadro de uma composição narrativa poética, conservase, normalmente, o termo estória/história, conservando-se o termo mythos quando se trata de narrações e personagens tradicionais
} 
Procederemos, desta forma, a uma sistematização do mito, no universo da cosmovisão ocidental, de forma quer a compreender a sua função social e imagética, no passado como na atualidade, quer a acompanhar a nascença do mito assim como da ciência que a ele se dedica: a mitologia.

2. Os mitos homéricos e sua evolução: presença de esquemas míticos na narrativa clássica

Os primeiros textos gregos conhecidos são aqueles que se pensa terem sido escritos por Homero (séc. VIII a.c.), no século VIII a.c ${ }^{10}$. Homero narra as vicissitudes e a vida dos Deuses, que partilham com o ser humano os seus sentimentos, os seus desejos, as suas vontades e as suas sensações. Os Deuses homéricos existem, assim, à imagem e semelhança do homem, pelo que, venerados e temidos, inculcam ao grego do século VIII a.c. uma conduta e um sistema de valores a seguir.

Para cantar a vida dos Deuses e dos heróis gregos, a Grécia criou o teatro. Este era, nos seus primórdios, uma manifestação religiosa consagrada ao culto dos Deuses; com o teatro nascerá a tragédia ${ }^{3}$ :

Assim acreditavam os antigos que começou a tragédia, afirmando que este nome vinha de tragos, que quer dizer cabra, porque os confrades ou devotos, nas suas cerimónias e bailes, iam disfarçados de sátiros, cobrindo o corpo com uma pele com uma longa cauda presa à cintura. Uma cabra era o prémio para o coro que cantasse ou representasse melhor o ditirambo, e sendo a cabra um animal consagrado a Baco, a associação do culto dionisíaco à tragédia torna-se inevitável (BURKERT, 2001, p. 63).

Contemporâneo de Homero, Hesíodo (séc. VIII a.c.), por seu lado, vai sistematizar a vida dos deuses. Na sua obra Teogonia, Hesíodo canta a história dos deuses da Grécia: primeiro teria sido o caos, depois a Terra, ter-se-ia seguido o Tártaro ou o abismo e, finalmente, o Eros ou o amor. Hesíodo pretende contar a origem, ou dito de outro modo, nomear os antepassados por ordem (arte, aliás, utilizada pelas famílias gregas mais importantes), narrando as gerações dos deuses:

Or donc, tout d'abord, exista Faille, puis, par après, Terre Large-Poitrine, base sûre à jamais pour tous les êtres,

\footnotetext{
${ }^{3}$ No século VIII. a.c. impõe-se na Grécia a utilização da escrita alfabética.
} 
Pour tous les immortels qui tiennent les cimes enneigées de l'Olympe, Et le Tartare plein de brouillard au fond de la terre où l'on chemine, Et aussi Éros, le plus beau des dieux qui ne meurent jamais (Théogonie, v. 116120).

Tentando dar resposta à questão da origem do mundo e dos deuses, o autor introduz um esquema genealógico, independente da psicologia e de rituais, «quase alegoria, invólucro narrativo de relações sequenciais claramente pensadas» (NAVARRO, 2005, p. 347):

Dites [Muses] comment sont Vénus à l'être les dieux et la terre, les fleuves et la mer sans limites, qui se gonfle et qui saute, la lumière des étoiles et le ciel vaste par-dessus, et quels dieux sont nés des premiers dieux qui donnent des biens, comment ils ont fait le partage, et reparti les honneurs, comment d'abord ils ont occupé tous les replis de l'Olympe (Théogonie, v. 108-113).

Na sequência de Hesíodo, o legendário poeta e músico Orfeu ${ }^{4}$ teria, igualmente, cantado a origem do mundo nos seus poemas cosmogónico-teogónicos, os quais se pensa terem dado origem a cultos secretos, os Mistérios $^{5}$ :

La voix d'Orphée vainement le convie à ses noces. Il y assista, à la vérité, mais n'y apporta ni paroles consacrées, ni visage joyeux, ni présage de bon augure. La torche même qu'il y tint brûla jusqu'au bout en sifflant avec une fumée qui faisait couler les larmes [...]. Car, tandis que la nouvelle épousée, en compagnie de la troupe des naïades, erre à l'aventure dans l'herbe, elle tombe, le talon percé par la dent d'un serpent. Quand le chantre du Rhodope l'eut assez pleurée sur la terre, ne renonçant pas à la chercher même chez les ombres, il osa descendre jusqu'au Styx par la porte du Ténare (Les Métamorphoses, X, 1-25).

\footnotetext{
${ }^{4}$ Cf. M.H.R. Pereira, Estudos de História da cultura clássica - cultura grega, vol. I, Lisboa, Fundação Calouste Gulbenkian, 1990, p. 314-317: «em 1962, surgiu em Derveni, próximo de Tessalónica, um achado sensacional: o papiro que tomou o nome da localidade [...]. Terá sido copiado, entre 350 e 300 a.c., de um original do séc. $\mathrm{V}$ a.c. e contém o que parece ser um comentário a uma teogonia e cosmogonia pré-socrática. $\mathrm{O}$ autor, efectivamente, desconhece Platão, mas leu os atomistas, e pende para as doutrinas de Anaxágoras; em certo passo trata da teogonia de Orfeu, fala de oráculos, libações mistas. Qual a extensão e relevo que nele assumia o Orfismo é, todavia, pouco claro. [...] O nome de Orfeu [...] é onde tudo vai dar. Não sabemos o que significava originariamente, nem se o seu possuidor era uma pessoa real».

${ }^{5}$ Cf. M.H.R. Pereira, Estudos de História da cultura clássica - cultura grega, op.cit., p. 309: «Se dispuséssemos apenas dos dados literários, não poderíamos recuar a data do início dos Mistérios além do séc. VII a.c., pois é essa a época de composição do mais antigo texto que lhes faz referência: o Hino Homérico a Deméter. Mas a arqueologia poderá levá-los até à época micénica, pois micénica é [...] a mais antiga planta do telestério».
} 
A narração e representação cénica das façanhas e proezas realizadas pelos deuses ou pelos heróis protetores ou fundadores das comunidades tinham como objetivo a fixação de ideais de conduta que deveriam ser seguidos por toda a comunidade grega. Esta visão mítica do mundo começa, contudo, já no século VIII a.c., a desintegrar-se, graças à tentativa de argumentação racional de alguns pensadores que procurarão o fundamento da própria realidade no universo do logos, recusando uma explicação mitológica da globalidade do mundo. Esta evolução do pensamento permite o nascimento de uma nova disciplina, a filosofia.

O nascimento da filosofia ${ }^{6}$ é acompanhado pelo nascimento dos primeiros protomitólogos que procurarão na razão a compreensão de fenómenos naturais, antes atribuídos a instâncias míticas. Neste sentido, a escola jónica (séculos VII-VI a.c.) - Tales (625-547 a.c.), Anaximandro (610-547 a.c.) e Anaxímenes (585-525 a.c.) - não tentará explicar a origem do cosmos visível através de doutrinas mitológicas, como as de Hesíodo ou de Homero, ou, ainda, as de fenícios, babilónios ou egípcios, defendendo a criação do mundo a partir de princípios ou raízes fundamentais que estariam na origem dos quatro elementos: terra, água, fogo, ar. Empreendendo a explicação da evolução do mundo a partir de um começo (archê), estes autores pré-socráticos transformaram a cosmogonia mítica numa «construção científica de hipóteses» (BURKERT, 2001, p. 52). Xenófanes (fim do século VI a.c.), um continuador da escola jónica, e primeiro autor que mencionará Homero, afirma que Homero e Hesíodo atribuíram aos Deuses todas as vergonhas e desgraças dos mortais, roubos, enganos e adultérios, havendo feito os deuses à sua imagem (LEVI-STRAUSS, 2000, p. 19). Ao invés destes autores, Xenófanes defende que os deuses não se poderiam assemelhar em forma nem em reflexão aos mortais.

Demócrito (420 a.c.) continua a análise cosmogónica do mundo, imaginando o atomismo (ponto de partida do materialismo). Ora, a evolução do pensamento racionalista permite, no século V-IV a.c., o nascimento da mitologia como uma proto-ciência do

\footnotetext{
${ }^{6}$ Cf. LEVI-STRAUSS, 2000, p. 19: «Houve na Filosofia, desde o tempo dos gregos até aos séculos XVIII e mesmo XIX - e ainda hoje, em certo sentido - uma discussão tremenda sobre a origem das ideias matemáticas: a ideia de linha, a ideia de círculo, a ideia de triângulo. Havia, fundamentalmente, duas teorias clássicas dominantes: a primeira era a da mente como uma tábua rasa, que nada tinha, no começo, dentro de si; tudo lhe chegava a partir da experiência. A segunda teoria clássica remonta a Platão, que defendeu que essas ideias de círculo, de triângulo, de linha, eram ideias perfeitas, inatas à mente, e é por existirem na mente que as somos capazes de projectar [...] na realidade. Actualmente todo este problema da experiência em oposição à mente parece ter uma solução na estrutura do sistema nervoso».
} 
pensamento. Serão, assim, os sofistas, retóricos contemporâneos de Sócrates (470-399 a.c.), aqueles que primeiro interpretam o mito. $\mathrm{O}$ interesse passa a ser colocado nos detalhes das narrações míticas, com o intuito de aí encontrar inverosimilhanças. Professores da jovem aristocracia ateniense, os sofistas (Protágoras, Górgias, Crítias e Pródico) - pessoas cultivadas - afluíam de todas as partes da Grécia para ministrar em Atenas, ganhando a vida ensinando. Tendo como principal objetivo convencer o Outro, os sofistas recorriam facilmente à demagogia e a um discurso falacioso para atingir os seus fins. Foram, desta forma, criticados por Sócrates por não procurar a Verdade, antes corrompendo os espíritos através do ensino e utilização de métodos discursivos cujo único propósito era o de enganar os auditores:

[Socrate] Tous ces particuliers mercenaires, que le peuple appelle sophistes et regarde comme ses rivaux, n'enseignent pas d'autres maximes que celles que le peuple lui-même professe dans ses assemblés, et c'est là ce qu'ils appellent sagesse. On dirait un homme qui, après avoir observé les mouvements instinctifs et les appétits d'un animal grand et robuste, par où il faut l'approcher et par où le toucher, quand pourquoi il s'irrite ou s'apaise, quels cris il a coutume de pousser en chaque occasion et quel ton de voix l'adoucit ou l'effarouche, après avoir appris tout cela par une longue expérience, l'appellerait sagesse, et l'ayant systématisé en un sort d'art se mettrait à l'enseigner, bien qu'il ne sache vraiment ce qui, de ces habitudes et de ces appétits, est beau ou laid, bon ou mauvais, juste ou injuste ; se conformant dans l'emploi de ces termes aux instincts du grand animal ; appelant bon ce qui le réjouit, et mauvais ce qui l'importune, sans pouvoir légitimer autrement ces qualifications; nommant juste et beau le nécessaire, parce qu'il n'a pas vu et n'est point capable de montrer aux autres combien la nature du nécessaire diffère, en réalité, de celle du bon (République, VI, 493a- 493c).

Sócrates busca, portanto, a verdade para além do Olimpo, julgando segundo a consciência e separando o bem do útil. Porém, diferindo de Sócrates na compreensão da verdade, o relativismo sofista contestava a existência de uma verdade universal: a verdade é, nesta corrente de pensamento, reduzida a uma mera perceção pessoal da realidade, já que depende, na íntegra, do ponto de vista. A ótica relativista aplicava-se às crenças religiosas, que os sofistas diziam articular-se em torno da questão da existência ou não dos deuses, os quais apenas serviriam para responder a necessidades individuais e sociais dos homens. 
Apesar de divergências de ordem filosófica, sofistas e Sócrates convergiam na crítica a uma conceção do mundo alicerçada, unicamente, nos mitos de deuses e heróis ${ }^{7}$. Na continuidade da perspetiva racionalista, um discípulo de Sócrates e, igualmente, adversário dos sofistas, Platão (427-347 a.c.), considera os Deuses homéricos como meras categorias míticas, ligadas à fábula e à imaginação.

Platão contraria a veracidade das narrações míticas atribuídas a Homero, sustentando que o homem primitivo, não podendo explicar o insólito e o desconhecido, imagina o que, atualmente, designamos por animismo coletivo. Segundo Platão, o mito não poderia ser interpretado alegoricamente nem se encontraria ligado a tendências profundas do ser humano. Na prossecução desta reflexão, na obra República (377 a.c.), Platão bane os poetas, sem excetuar Homero, acusando as narrações míticas Odisseia e Ilíada de conter falsas concepções teológicas, e, como tal, apresentando maus exemplos à juventude:

[Socrate] Ceux-ci [Homère et Hésiode], en effet, ont composé des fables menteuses que l'on a racontées et qu'on raconte encore aux hommes. [Adimante] Quelles sont ces fables, demanda-t-il, et qu'y blâmes-tu ? [Socrate] Ce qu'il faut, répondis-je, avant tout et surtout blâmer, particulièrement quand le mensonge est sans beauté.

[Adimante] Mais quand est-ce?

[Socrate] Quand on représente mal les dieux et les héros, comme un peintre qui trace des objets n'ayant aucune ressemblance avec ceux qu'il voulait représenter.

$[\ldots]$

Donc, il nous faut d'abord, ce semble, veiller sur les faiseurs de fables, choisir leurs bonnes compositions et rejeter les mauvaises. Nous engagerons ensuite les nourrices et les mères à conter aux enfants celles que nous aurons choisies, et à modeler l'âme avec leurs fables bien plus que le corps avec leurs mains ; mais de celles qu'elles racontent à présent la plupart sont à rejeter (République, II, 377b-378b).

A poesia e, portanto, os mitos, eram considerados como uma mera reprodução fictícia da realidade ${ }^{8}$, reportando-se, sobretudo, ao conteúdo, e menos aos efeitos que poderiam gerar:

\footnotetext{
${ }^{7}$ Sócrates e sofistas são os responsáveis pela instauração da filosofia, como disciplina, em Atenas.

${ }^{8}$ Platão não nega, no entanto, o prazer que obtemos da leitura dessas narrações míticas (Cf. Platão, $L a$ Republique, Livro I, Livro III e Livro X): «nous prierons Homère et les autres poètes de ne point trouver mauvais que nous les effacions [certaines passages relatives à l'Hadès]; ce n'est point qu'ils manquent de poésie, et ne flattent l'oreille du grand nombre mais, plus ils sont poétiques, moins il convient de les laisser entendre à des enfants et à des hommes qui doivent être libres» (République, III, 386d-387d).
} 
Or donc, poserons-nous en principe que tous les poètes, à commencer par Homère, sont de simples imitateurs des apparences de la vertu et des autres sujets qu'ils traitent, mais que, pour la vérité, ils n'y atteignent pas : semblables en cela au peintre dont nous parlions tout à l'heure, qui dessinera une apparence de cordonnier, sans rien entendre à la cordonnerie, pour des gens qui, n'y entendant pas plus que lui, jugent des choses d'après la couleur et le dessin (République, X, 600c-601c).

Mythos, linguagem da criação - que se opõe a $\log o s$, linguagem da demonstração era, desta forma, encarado como uma narrativa fantasiosa que apenas traduzia uma imagem da existência ${ }^{27}$. Na obra mencionada - libelo de defesa de uma cidade-estado ideal -, Platão compendia críticas ao que considera ser a poesia imitadora, denunciando «toutes les oeuvres de ce genre» que «ruinent, ce semble, l'esprit de ceux qui les écoutent lorqu'ils n'ont point l'antidote, c'est-à-dire la connaissance de ce qu'elles sont réellement» (République, X, 595a595e). Continuando a demonstração do seu juízo, Platão explica-nos o porquê da inverosimilhança da imitação relativamente à verdade:

[Socrate] Ainsi, il y a trois sortes de lits ; l'une qui existe dans la nature des choses et dont nous pouvons dire, je pense, que Dieu est l'auteur [...] Une seconde est celle du menuisier [...] Et une troisième, celle du peintre $[\ldots]$.

Ainsi, peintre, menuisier, Dieu, ils sont trois qui président à la façon des trois espèces de lits.

$[\ldots]$

[Glaucon] Il me semble que le nom qui lui [peintre] conviendrait le mieux est celui d'imitateur de ce dont les deux autres sont les ouvriers. [Socrate] Soit. Tu appelles donc imitateur l'auteur d'une production éloignée de la nature de trois degrés. [...] Donc, le faiseur de la tragédie, s'il est imitateur, sera par nature éloigné de trois degrés du roi et de la vérité (République, $\mathrm{X}$, 597b-597e).

Ora, segundo Platão, os poetas trágicos, afastando-se da verdade em terceiro grau, criam fantasmas e distanciam-se da realidade, não possuindo os conhecimentos necessários das coisas que imitam; nesse sentido, o imitador conhece, apenas, a aparência do que imita, desconhecendo a beleza e os defeitos das coisas imitadas: «l'imitateur n'a aucune connaissance valable de ce qu'il imite, et l'imitation n'est qu'une espèce de jeu d'enfant [...] ; ensuite, ceux qui s'appliquent à la poésie tragique, qu'ils composent en vers iambiques ou en vers épiques, sont des imitateurs en Suprême degré.» (République, VI, 602b) ${ }^{28}$. 
Apesar da crítica aos mitos homéricos, pois «si l'on prétend que Dieu, qui est bon, est la cause des malheurs de quelqu'un, nous combattrons de tels propos de toutes nos forces» (République, II, 380a-381b), Platão utiliza, contudo, o mito para explicar as leis do cosmos. Na obra Timeu (360 a.c.), o autor considera o criador do mundo como um artesão, um demiourgos, que havia formado este mundo «tão completo quanto possível, como uma ordem, que, no seu cerne, é uma harmonia matemática, conquistada a uma matéria que se lhe opõe» (BURKERT, 2001, p. 53). Assim, os pormenores "foram conquistados a partir de um saber matemático e astronómico, observações e hipóteses, e [os pormenores] já não estão dependentes de tradições míticas da humanidade; o quadro de conjunto, todavia, sobretudo na sua relação com Deus e a alma, tomou em breve novamente uma função mítica, como matriz orientadora da compreensão do mundo" (BURKERT, 2001, p. 53).

A perspetiva platónica da criação do mundo encontrar-se-á, deste modo, subjacente à religião, e, não se tendo conseguido distanciar, como pretendera, de uma imagem mítica, conservar-se-á no universo medievo-cristão ocidental.

Aristóteles (384-322 a.c.), discípulo de Platão, e, mais tarde, preceptor de Alexandre O Grande (356-323 a.c.), funda, em 355 a.c., em Atenas, a sua própria escola - o Liceu -, também chamada de Escola Peripatética ${ }^{9}$. Na esteira de Platão, Aristóteles considerará que «l'épopée, la poésie tragique, la comédie, le dithyrambe, et en grande partie le jeu de la flûte et de la cithare» (Poétique 1) são artes imitativas. A poesia teria, assim, a sua origem na imitação, «parce qu'imiter est naturel aux hommes» (Poétique 4), e subdividir-se-ia em três géneros: a tragédia (cantada por poetas épicos), a comédia (cantada por poetas iâmbicos) e a epopeia. Tragédia, comédia e epopeia tinham, por seu lado, em comum, o facto de serem histórias (que, na época clássica grega, eram designadas mythos): «On ignore qui a introduit les masques $\square$ dans la comédie $\square$, les prologues, qui a définit le nombre des acteurs et tous les détails de ce genre, mais l'idée de composer des histories [mythos] remonte à Épicharme et à Phormis» (Poétique 16). Sendo a poesia uma arte imitativa, o objetivo do poeta não deveria ser o de dizer «ce qui est réellement arrivé, mais de dire ce qui pourrait arriver selon la vraisemblance ou selon la nécessité» (Poétique 9$)^{10}$. Mito, enquanto conteúdo da poesia, deveria imitar «soit des choses qui ont existé ou qui existent, soit des choses dont on prétend

\footnotetext{
${ }^{9}$ Aristóteles fundará esta escola aos 50 anos, chamada de Liceu devido ao local no qual se encontrava (próximo do templo consagrado a Apolo Lykeios). O filósofo ensina, passeando-se com os alunos, razão pela qual esta escola foi designada de escola Peripatética. De manhã, Aristóteles ministrava aulas de esoterismo, reservadas aos discípulos mais avançados, e, de tarde, dava conferências esotéricas, abertas ao público.

${ }^{10}$ Aristóteles estabelece, já no século IV a.c., a diferença entre um poeta e um historiador, considerando que este último tinha como propósito «raconter des événements qui sont réellement arrivés» (Poétique 9).
} 
qu'elles existent, ou qui le paraissent, soit des choses qui devraient exister» (Poétique 24). $\mathrm{O}$ poeta, caso não imitasse a realidade, ter-se-ia de manter fiel à verosimilhança do objeto imitado. O mito poderia, neste contexto, ser uma história real ou inventada, uma vez que o importante seria que pudesse ser tomada como verdadeira pelos leitores e/ou auditores: «Dans l'épopée il faut préférer ce qui est impossible mais vraisemblable à ce qui est possible, mais incroyable, et ces récits ne doivent pas être composés de parties irrationnelles» (Poétique 24). A imitação poética aristotélica caracteriza-se, em suma, por não ser uma imitação das coisas mas uma imitação dos atos, os quais deveriam ser possíveis, e não reais.

Para Platão, também a arte era imitação. Aristóteles, porém, utilizando o mesmo termo que o antigo Mestre, altera-lhe o sentido, atribuindo-lhe uma nova significação. Continuando a considerar a arte como uma ação imitativa, Aristóteles deixa de a considerar como enganadora ou simulacro, como defendera a perspetiva platónica. A imitação tem, apesar disso, de obedecer a certas regras: dependendo da verosimilhança, deve imitar «des hommes meilleurs que nous, il faut imiter les bons portraitistes, car pour rendre la forme propre du modèle, ils peignent en plus beau, tout en faisant des portraits ressemblants» (Poétique 16). Aristóteles considera, por conseguinte, a tragédia como a imitação poética por excelência, superior à comédia, já que esta imita homens de carácter inferior: «le comique est un défaut et une laideur sans douleur ni dommage, de même que le masque comique est laid et difforme, sans exprimer douleur» (Poétique 5). Por outro lado, a epopeia, superior à comédia, situa- se num estádio inferior à tragédia, porque, mesmo se «l'épopée ressemble à la tragédie en tant qu'elle imite [...] des hommes de haute valeur» (Poétique 5), os elementos da epopeia encontrar-se-iam na tragédia, enquanto «tous ceux de la tragédie ne sont pas contenus dans l'épopée» (Poétique 5).

A mitologia grega dominará toda a Idade Média e o Renascimento Ocidentais, constituindo a base imagético-cultural do imaginário europeu contemporâneo ${ }^{11}$. Será, desta forma, objeto de estudo e razão de ser de uma nova ciência.

\footnotetext{
${ }^{11}$ Cf. BURKERT, 2001, p. 29: A mitologia grega, que, não deve, porém, ser confundida com as narrativas mágicas, uma vez que estas apresentam determinadas especificidades. Assim, a «singularidade da mitologia grega, em contraste com as de outros povos, pode, inicialmente, conceber-se de preferência como negativa: o elemento mágico passa para segundo plano - quase não há mitos de encantamento e de desencantamento; também a narrativa-advertência (cautionary tale) mal se encontra na sua forma pura. A maior parte das histórias antigas são de qualquer forma ambivalentes, susceptíveis de interpretações diversas».
} 


\section{O estabelecimento da mitologia como ciência}

O nascimento da ciência mitológica acompanha o universo mitológico do Homem ao longo da História.

Num momento em que o teocentrismo religioso já se encontrava fortemente instalado no mundo ocidental, a Idade Média foi confrontada com dois modos de pensamento, aparentemente contraditórios: por um lado, a celebração do panteão greco-romano, e, por outro, a glorificação de um único Deus cristão. A Idade Média conheceu, desta forma, a interpenetração do universo mitológico antigo e do universo monoteísta cristão; apesar disso, o teocentrismo vingaria.

Após anos de teocentrismo, um novo período da História da Europa vai, contudo, permitir a renascença de uma visão antropocêntrica do mundo: o Renascimento ${ }^{12}$. O vigor original dos mitos e a sua consistência são recobrados neste período que busca a sua fonte na Antiguidade clássica greco-latina. Este novo vigor e consistência são, todavia, atenuados com o advento da Contrarreforma, que restabelece, no mundo ocidental europeu, uma conceção teocêntrica dominante.

Apesar deste domínio imagético, o teocentrismo religioso não impedirá, contudo, a manifestação de elementos míticos, que com ele se mesclarão (cf. CARLIER \& GRITON, 1994).

A interpenetração do universo mítico e do universo religioso atinge o seu paroxismo no século XVIII, quando, após um período de forte teocentrismo, mito e poder se confundem «sous le regard bienveillant de l'Église» (CARLIER \& GRITON-ROTTERDAM, 1994, p. 59). É, igualmente, neste mesmo século, que razão e progresso dão azo a uma revolução intelectual, fervorosamente anti-mitológica (CARLIER \& GRITON-ROTTERDAM, 1994, p. 94). Neste contexto de racionalismo antissimbólico e anti-mitológico, anunciador do cientismo do século seguinte, o mito torna-se, gradualmente, objeto de investigação científica.

O Iluminismo defende a independência e a liberdade da razão perante os mitos e as verdades, que, porque impostas, são consideradas como uma fonte de erros e uma base para a dominação dos homens. Segundo os iluministas, a aceitação e a compreensão de uma

\footnotetext{
${ }^{12}$ Cf. BOIA, 2006, p. 71: Separando- se da Idade Média «par sa soif de liberté et par l'affirmation de l'individu et de l'individualisme», o Renascimento cultivará a beleza do corpo, a qual constitui «l'un de ses symboles les plus caractèristiques».
} 
verdade deveriam depender da liberdade de reflexão, pelo que o Homem deveria rejeitar todos os erros resultantes de verdades impostas; nesse sentido, apenas poderíamos aceder à verdadeira verdade após um juízo livre e independente:

\begin{abstract}
Or, pour propager les Lumières, il n'est rien requis d'autre que la liberté ; et, à vrai dire, ce qu'il y a de plus inoffensif sous ce nom, à savoir la liberté de faire un usage public de la raison dans tous les domaines. [...] Un prince qui ne trouve pas indigne de lui de dire qu'il considère comme un devoir, en matière de religion, de rien prescrire aux hommes [...] Sous son règne, il est permis à d'honorables prêtres, en qualité de savants, sans préjudice des devoirs de leur charge, d'exposer librement et publiquement au monde, pour examen, leurs jugements et leurs vues qui s'écartent ici ou là du symbole reçu (KANT, 2006, p. 6-8).
\end{abstract}

No domínio da crítica mitológica, o século XVIII é, portanto, o século da desmitificação do irracional. Porém, apesar da defesa de uma submissão do Homem à racionalidade que, naturalmente, lhe subjaz, a desmitificação do irracional coabita com uma arte pictórica fortemente marcada por elementos mitológicos. Esta ambiguidade entre uma representação visual mitológica, e uma teoria que se baseia na razão, faz com que o século XVIII oscile entre a crítica simbólico-religiosa (mitológica), de filósofos e escritores, e a representação pictórica de cenas da vida imaginária de deuses e de heróis, por parte de artistas plásticos.

O século XIX - que, em termos sociais, assiste à consolidação da burguesia como classe social e ao desenvolvimento da indústria e do cientismo ${ }^{13}$ - inaugura, por seu lado, a utopia científica. Assim sendo, também filósofos positivistas e românticos, no seguimento da racionalidade iluminista do século XVIII, se rebelam (como Platão, aliás, já o fizera no século V-IV a.c), contra a irracionalidade das fábulas:

\begin{abstract}
A la suite de Fontenelle, Montfaucon ou Bayle voudraient percer la cause première de ces récits légendaires. Dans l'Émile (1762), Rousseau explique l'apparition du mythe par la conjonction de l'ignorance et de l'imagination primitives : [...] l'homme a commencé par animer tous les êtres dont il sentait l'action; faute de connaître les bornes de leur puissance, il l'a supposé illimité, et en a fait des dieux. Cette explication qui manque un peu de chaleur, est révélatrice d'un nouvel état d'esprit
\end{abstract}

\footnotetext{
${ }^{13}$ O século XIX é o século de Lamarck (1744-1829) e de Darwin (1809-1882) (Darwin publica A Origem das Espécies em 1859). É, igualmente, o século da filosofia positivista, fundada por Auguste Comte (1798-1857), e o século dos estudos folclóricos. É, assim, William J. Thoms (1803-1885), um erudito que se interessava pelas tradições populares, que cria a palavra Folklore.
} 
marqué par la défiance et la critique des illusions. Au reste, Rousseau n'a pas tort de remarquer : L'ancien paganisme enfanta des dieux abominables, qu'on ềt punis ici-bas comme des scélérats, et qui n'offraient pour tableau du bonheur suprême que des forfaits à commettre et des passions à contenter (CARLIER \& GRITON-ROTTERDAM, 1994, p. 60).

Porém, a mitologia não deixará, tal como no século precedente, de deixar as suas marcas quer na literatura, quer nas artes visuais. No início do século XIX, as representações artísticas colocam em relevo os ciclos heróicos das lendas alemãs e os décors da Idade Média. Paralelamente, o Romantismo abre-se ao mito através das fábulas e das lendas. A mitologia serve, por conseguinte, para enriquecer a realidade, forjando, em simultâneo, novos mitos: «Dans la Légende des Siècles (1859-1883), Hugo embrasse dans un même souffle épique le monde biblique, les exploits homériques et les combats de Charlemagne. Durandal fait pendant au bouclier d'Énée. Panthéon antique et Histoire française se mêlent et se complètent» (MÜLLER, 2002, p. 63).

No seguimento da fabulação literária do Romantismo, a segunda metade do século XIX assiste ao nascimento do estudo científico dos contos e das lendas populares; paralelamente, a mitologia nasce e assume-se como ciência. Neste contexto, Max Müller (1823-1900), fundador da mitologia moderna, tenta encontrar uma resposta a problemáticas fundamentais da mitologia. Questiona, por conseguinte, o nascimento, o desenvolvimento e o significado dos mitos:

Nous parlons encore du soleil levant et du soleil couchant, d'arcs-en-ciel, de coups de tonnerre, parce que le langage a sanctionné ces expressions. Nous les employons, quoique nous n'y croyions pas. Mais comment, à l'origine, l'esprit humain fut-il amené à de telles imaginations ? Comment les noms et les fables se formèrent-ils? Si nous ne trouvons pas de réponses à ces questions, il nous faut renoncer à croire que l'intelligence humaine a suivi dans tous les siècles et dans tous les pays une marche constante et régulière, qu'elle a toujours été en progrès (MÜLLER, 2002, p. 20).

Para o estudo da mitologia, Müller problematiza e reflecte sobre a evolução do Homem. Considera, por conseguinte, que a humanidade encerra períodos históricos distintos. Nesta temporalização histórica, Müller defende que o aparecimento da linguagem é concomitante com o surgimento da inteligência humana, ambos constituindo o primeiro ciclo da humanidade - o período dos dialetos (MÜLLER, 2002, p. 5). Segue-se o período 
mítico (antecessor do período das nações), ao qual corresponde a existência de uma idade mitológica, e, portanto, criadora de mitos (MÜLLER, 2002, p. 5).

Müller considera, deste modo, que os mitos são, originariamente, palavras (MÜLLER, 2002, p. 41). Nesse sentido, compara a origem e significado de várias palavras, em diferentes línguas. Através deste método comparativo, Müller dá origem a uma nova disciplina; à nova ciência mitológica, Müller acresce a Mitologia Comparada ${ }^{47}$ :

Hegel appelle la découverte de l'origine commune du grec et du sanskrit la découverte d'un nouveau monde ; la même chose peut se dire aussi de l'origine commune de la mythologie grecque et de la mythologie sanscrite. La découverte est faite, et la science de la mythologie comparée s'élèvera bientôt à la même importance que la philologie comparée (MÜLLER, 2002, p. 91).

Ao considerar os mitos como palavras, a ciência mitológica de Müller encara a mitologia como uma antiga forma de linguagem (MÜLLER, 2002, p. 91). Apesar de esta definição de mitologia se encontrar, hoje em dia, ultrapassada, é, todavia, graças a Müller que a ciência mitológica, independente da Filosofia, da História, da Religião e da Ética, se assume como uma ciência deveras autónoma.

$\mathrm{Na}$ esteira de Max Müller ${ }^{14}$ os estudos mitológicos ulteriores tentarão, sobretudo nas narrativas de heróis, explicar a transmissão mitológica através da explicação alegórica, em particular a partir do percurso solar. Esta perspetiva foi sendo desacreditada, considerandose, atualmente, que «a referência à Natureza é um dos níveis das aplicações míticas, ocasionalmente o preferível, contudo não é a origem nem o sentido completo da narrativa» (BURKERT, 2001, p. 32). Ter-se-á, porém, de aguardar a eclosão do século XX, em particular a chegada dos estudos freudianos, para compreender a parte de realidade existente no mito.

Esta será, no entanto, matéria que desenvolveremos num segundo artigo, cuja publicação procederá ao presente trabalho.

\footnotetext{
${ }^{14}$ Max Müller influenciará os trabalhos de Freud. Para Müller, em Contributions to the science of mythology, o totem é uma insígnia do clã, um nome de clã, um nome de um ancião do clã e/ou um nome de um objecto venerado pelo clã. Cf. FREUD, 1986, p. 128.
} 
A. M. Saldanha

\section{Referências}

ARISTÓTELES. Poétique. Paris: Mille et Une Nuits, 1997.

BURKERT, W. Mito e Mitologias. Lisboa: Edições 70, 2001.

CARLIER, C. \& GRITON-ROTTERDAM, N. Des mythes aux mithologies. Paris: Marketing, 1994.

FREUD, S. Totem et tabou. Paris: Petite Bibiothèque Payot, 1986.

HESIODE. Théogonie et autres poèmes seuivi des Hymnes homériques. Paris: Gallimard, 2001.

HORACE. Oeuvres Complètes. Paris: J.-J. Dubochet, Le Chevalier et Ce, 1848.

KANT, E. Qu'est-ce que les Lumières? Paris: Hatier, 2006.

LAPIERRE, S. Les Sophistes. Montréeal, Collège de Bois-de- Boulogne. Disponível em: http://www.colvir.net/prof/serge.lapierre/Sophistes.html

LÉVI-STRAUSS, C. Mito e significado. Lisboa: Edições 70, 2000.

MÜLLER, M. Mythologie comparée. Paris: Robert Laffont, 2002.

NAVARRO, F. (dir). História Universal. Tomos I, II e VII. Portugal: Salvat, 2005.

PLATÃO. La République. Paris: Flammarion, 1966.

Artigo recebido em: 16/08/2018

Artigo aceito para publicar em: 08/10/2018 